\title{
ACTIVITIES FOR PHYSICALLY DISABLED IN ISOLATION OF COVID-19 PANDEMIC
}

aUsama Bin Yar

Post-Graduate Student, Department of Orthotics \& Prosthetics Government College University, Faisalabad (GCUF).

\section{ABSTRACT:}

Disability is one of a major health problem and billions of disables are suffering in these days of the corona virus epidemic. As every individual has confined himself in quarantine including disable people. And on the other hand, most importantly people suffering from disabilities are under-going compromised rehabilitation, which ultimately has an adverse effect not only on their health but also on mental health. So, to compensate for their physiological loss, it is necessary to guide the disable community about their health and especially maintaining it through exercise as it is a major healthcare concern nowadays.

To overcome such healthcare issues, especially in the case of disabled population, the main aim is to recommend a set of exercises and physical activities to remain fit and active in isolation. The exercises are suggested for amputees, handicapped and bedridden patients. Doing exercise will not only maintain the physical health of disable ones but also improve mental health. Mental health is more important for disable people as they are emotionally sensitive and weak health-wise.

\section{KEYWORDS:}

Coronavirus, COVID-19, Disability, Pandemic, Exercises, Impairments, Mobility, Physically Disabled, Physical Activities.

\section{How to cite this:}

doi:https://doi.org/10.37723/jumdc.v12i3.544

Yar UB. Activities for physical disabled in isolation of COVID-19 pandemic. Journal of University Medical \& Dental College Faisalabad. 2021;12(3):222-229. https://doi.org/10.37723/jumdc.v12i3.544

This is an Open Access article distributed under the terms of the Creative Commons Attribution License (http://creativecommons.org/licenses/by/4.0), which permits unrestricted use, distribution, and reproduction in any medium provided the original work is properly cited. 


\section{INTRODUCTION:}

Disability is a segment of human vitality. Permanently or temporarily almost everyone is impaired at some turn of life and those who survive to old age will experience increasing difficulties in functioning. Disability Discrimination Act (DDA) 1995, states and defines that:

"Disabled is one whose 'normal day-to-day functioning' is severely impaired in terms of agility, manual dexterity, physical-coordination, continence, ability to pick, hold or push or capacity to focus, which eventually disrupts normal physiological potential" ${ }^{[1]}$.

Additionally, according to World Health Organization Disabilities (WHO):

"Disability is a term which encompasses impairments that limits activities and restricts participation" [2].

Moreover, a physical disability is the long-term impairment or inability of part or of a human bodily function, which results in restrict physical activity and loss of agility or endurance. Because of functional impairments a person faces failure in executing normal bodily movements such as; walking, balancing, sitting, standing, controlling muscles, using hand and arms etc. There are two main types of physical disabilities; the musculoskeletal disability and the neuromuscular disability. Both types of disabilities result in impediment to routine work and activities. Coming to the point, globally the population of disables is increasing, many of them face difficulties to involve themselves in physical activities. Opting healthy lifestyle with a disability can be a challenging task ${ }^{[3,4]}$. Performing inadequate exercise is a serious public health concern for all individuals, but individuals with disabilities are at threat of having serious health issues linked with physical inactivity ${ }^{[5]}$. Functions that are effortlessly achieved by young adults, such as switching from a wheelchair to an automobile, climbing a ramp or walking with braces, can become a significant hurdle for individuals aging with a physical disability and often need additional support from peers, family members, and personal assistants. In some ways, it is more important to meet the physical fitness needs of middle and aged individuals than in the general community. While, a minor decrease in strength and endurance may diminish the physical independence of an individual. Such secondary disorders including; fatigue, deconditioning, chronic-pain, sudden weight gain, pressure ulcers, spasticity or compromised thermo regulation results in serious reduction in mobility, health and furthermore, cause limitations in activities and impairments ${ }^{[6]}$.

Corresponding Author:

Usama Bin Yar

Post-Graduate Student, Department of

Orthotics \& Prosthetics Government College

University, Faisalabad (GCUF).

Email: musamabinyar.14@gmail.com

According to the Worldometer about $181,260,371$ cases are confirmed and approximately $3,926,987$ deaths are claimed with $165,839,789$ recoveries till June, $2021^{[7]}$. People are staying at home and it include both physically normal and physically disabled persons. As the world is hit by a drastic pandemic, which has changed the entire pattern of living and everyone is in tough situations. Before this every disable use to go to their rehabilitation centers for followups, but today due to lockdown and social ups and downs physically disabled persons are lacking rehabilitation, their proper assistance is being overlooked, their physical health is being subsided, and most importantly their quality of life is being impaired. While, remaining at home is not just affecting their physical health but also their mental health gradually. To help the community, it is necessary to have some guidelines to opt regarding home-based functioning.

While, to live healthy and active life in pandemic, exercise is a key to survive. Therefore, it is necessary for physically disabled to perform recommended exercises to gain mobility, strength, endurance and specially to maintain mental health. Performing a set of exercises in epidemic isolation will surely stand-out with positive outcomes for physically disabled persons as well as normal persons ${ }^{[8,9]}$. 


\section{RECOMMENED ACTIVITIES}

\section{1) EXERCISES (Physical Activities):}

Exercise is essential for health to maintain and enhance better living. These recommendations cover exercises for amputees (an individual's undergone amputation.), handicapped (an individual restricting ability to function physically, mentally or socially.) and bedridden-patients (an individual restricted to bed by sickness or old age). Following exercises include ROM and mobility-enhancing exercises, which should be done regularly and in a proper set of repetitions:

a) For Amputees:

Lower limb amputee has lower exercise capacities, proportionally to the delay necessary to use their well-fitted prosthesis. Exercise training is a valid therapeutic to improve local factors (residual limb), muscle strength and endurance, locomotor performance and to decrease the cardiovascular risk factors ${ }^{[10,11]}$. Thus, following are weight bearing and balance exercisessuggested training for amputees restricted or isolated in specific premises:

1) Partial-Weight Bearing Exercises:

- Dual-Hand Supported Walk.

- Single-Hand Supported Walk.

- Finger-Tip Supported Walk.

- Walk without support.

2) Partial-Weight Shift Exercises:

- Shift weight from one leg to another using both hands.

- Shift weight from one leg to other using contralateral hand support.

- Walking without the support.

- Rotating pelvic-girdle.

- Walking sideward using support of both hands.

- Weight shifting using both hands.

- Weight shifting without any support.

- Obstacle crossing with or without any support.

3) Functional Exercises:

- Climbing up and down the stairs (for below knee amputees).

- Sitting down and getting up from the floor.

- Sitting and getting up from a chair (for bilateral amputees).

- Carrying weight (as it increases endurance and balance).

b) For Handicapped Individuals:

Exercise training and wheelchair mobility skills (WMS) training can lead to a sustained improvement in physical activity (PA) in a manual wheelchair physical fitness, functional independence and rehabilitation outcome of wheelchair users ${ }^{[12,13]}$. Thus, following are several exercises suggested training for handicapped individuals, especially for wheel-chair users:

- Bicep Curls: Hold dumbbell in both hands, and stretch arms outward with palms pointing upward. Bring the dumbbell up towards the shoulder without moving your elbows.

- Toe Taps: Sit straight with contracted abs and feet on the floor. Slant the toes up towards the roof and then put back down to the floor. Repeat it for certain times.

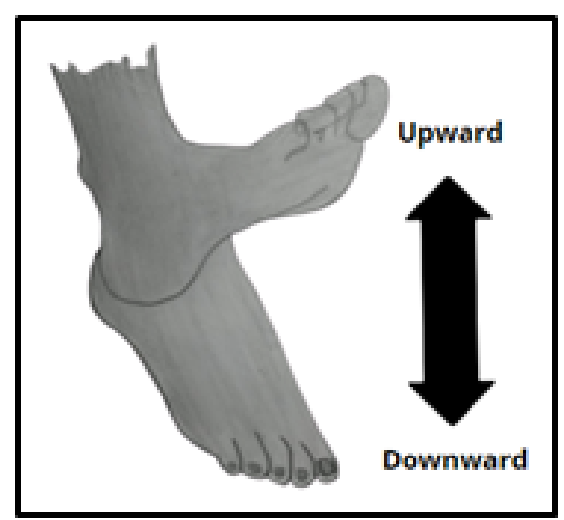

Figure-I: Moving upward and downward to achieve toe taps.

Trunk Twist: Sit straight with contracted abs and feet on the floor. Hold shoulder-girdle with opposite hands while arms residing your chest and elbows on sides. Rotate upper-body to right then to left and repeat it several times.

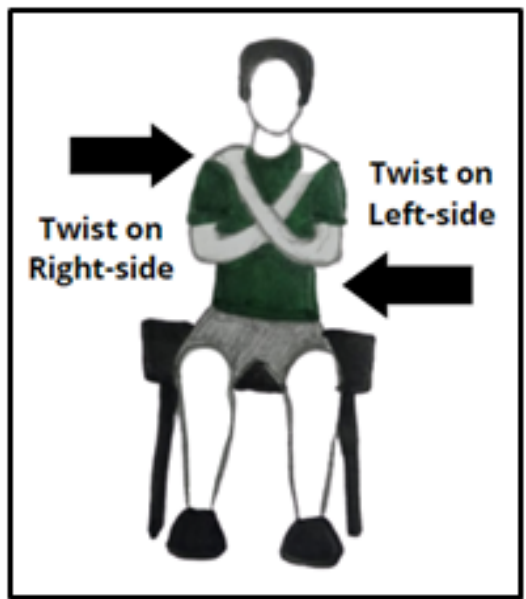

Figure-II: An elaboration to do truck twist. 
Captain's Chair: Sit straight and put both hands on arm of chair. Gradually raise both legs off the floor and bend towards the chest and lift entire body using your arms. After that lift back down to chair's seat and repeat this cycle again.

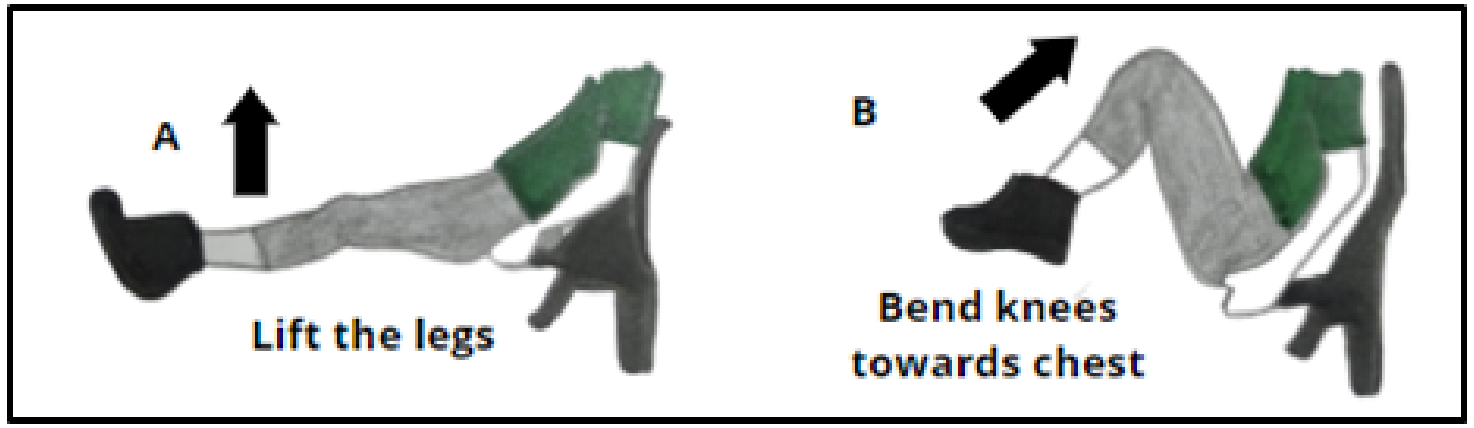

Figure-III: Illustration of performing captain's chair exercise.

Side Bend Stretch: Sit straight, engaging ab muscles and hips. Raise arms up towards the roof and keep arms near to ear. Join both hands in air and gradually bend entire upper-body to each side and make " $C$ " with the spine. Keep stretching for 5-15 seconds and steadily return to middle and repeat it on the other side.

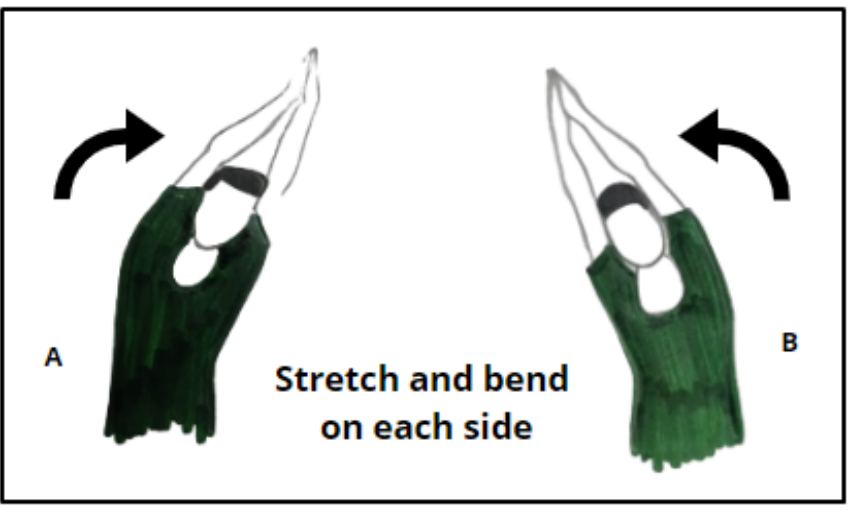

Figure-IV: Illustration of side bend stretch exercise.

\section{c) For Bedridden Individuals:}

Bedridden patients are at high risk as they develop perilous complications including; pressure sores, muscle atrophy, contractures dementia etc. Thus, physical mobility is important for bedridden patients ${ }^{[14,15]}$. So, following are some passive and active exercises that are recommended for bedridden individual:

Palm Press: It is the easiest exercise that could be performed in bed. Hold the rubber ball in the palm and press the ball inward with fingers. Repeat it several times in reps as it gains tolerance and mobility.

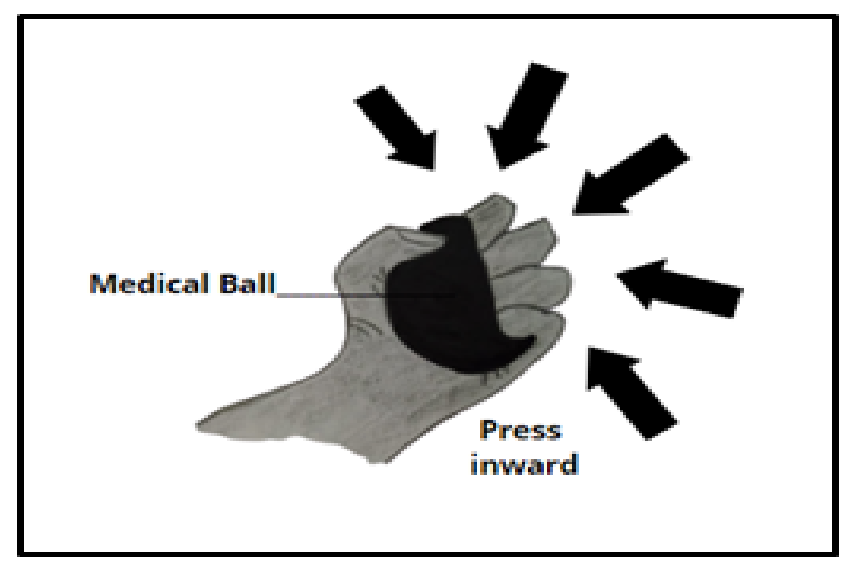

Figure-V: Demonstration of performing palm press exercise.

Arm Lifting: Lift each arm above the head as far as possible, hold it above for few seconds and then gradually bring it down. Repeated it several times to retain body mass. Moreover, it is suggested to enhance strength and mobility in upper-body.

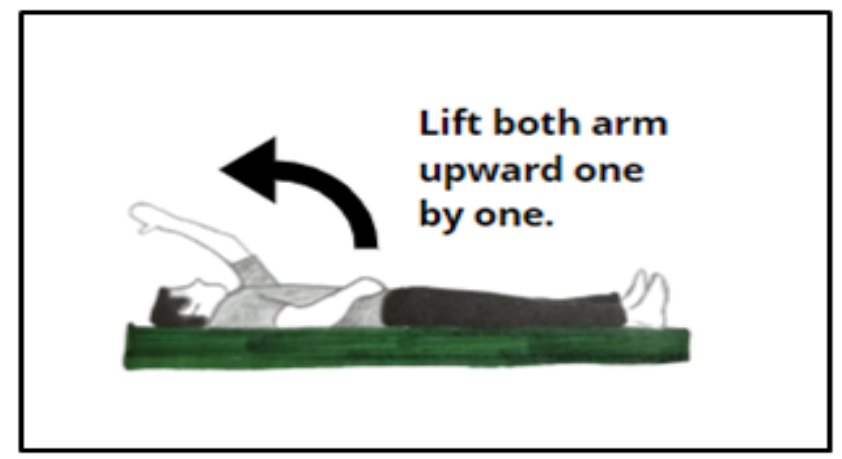

Figure-VI: Demonstration of lifting arms while lying in bed. 
Wrist Rotation: Hold the forearm and rotate the wrist in clockwise direction. Rotate for several times and switch the direction to anticlockwise. Repeat it counting the rounds. Perform it for 10-15 seconds as this movement is strongly recommended for bedridden individuals as it provides strength and mobility to the wrist.

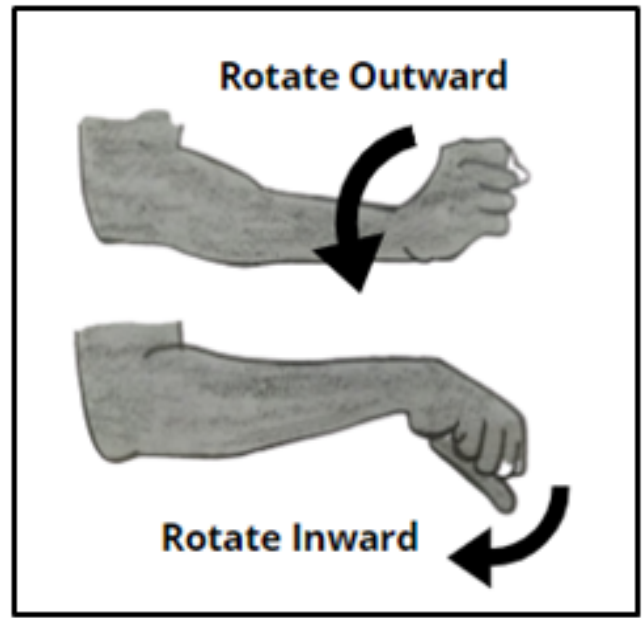

Figure-VII: Illustration of rotating wrist clockwise (outward) and anticlockwise (inward).

Ankle Flexion: Help patient to get in supine position and move the foot in dorsiflexion and plantar-flexion until the stretch is felt. Repeat the movement several times. This exercise is necessary as it ameliorates ROM and elevates blood supply in the ankles.

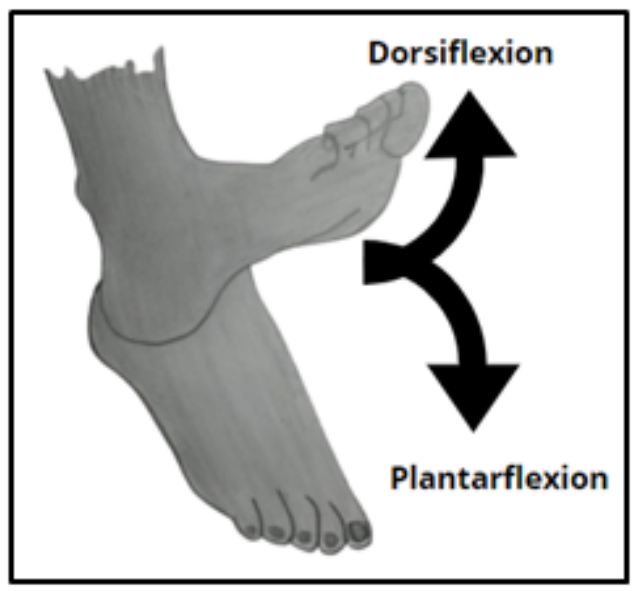

Figure-VIII: Demonstration of dorsiflexion and plantar-flexion.
Leg Lifting: Help patient to get in supine position, as it should be performed by assistants. Elevate the leg toward roof clockwise, to achieve 90 degrees. Hold the leg for certain duration and slowly push towards the head while watch for the facial expressions of patient, as angle increases. Repeat several times to improve ROM and overall strength in lower-limbs.

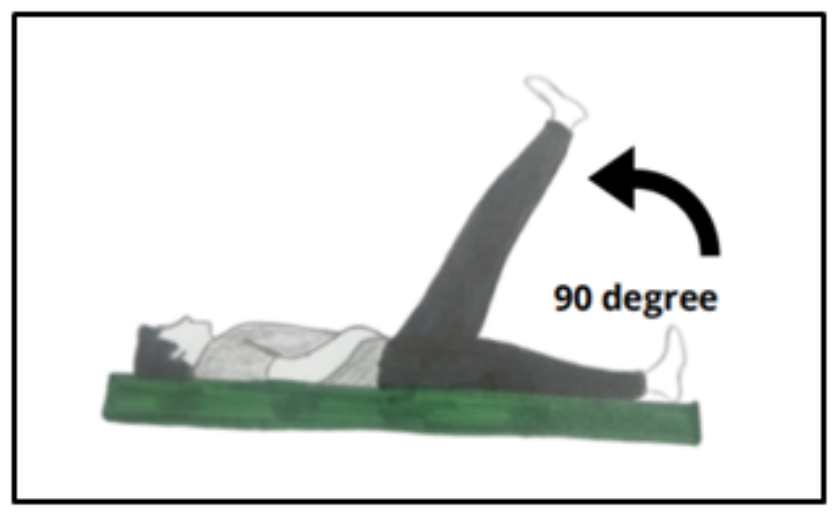

Figure-IX: Exhibition of leg lifting exercise.

Hamstring Stretch: This exercise is the safest and simplest exercise for individuals with hamstring issues. Help patient to get in supine position, the assistants should elevate each leg and move it toward the chest with the straight knee. Keep it there for couple of seconds to return to the original point.

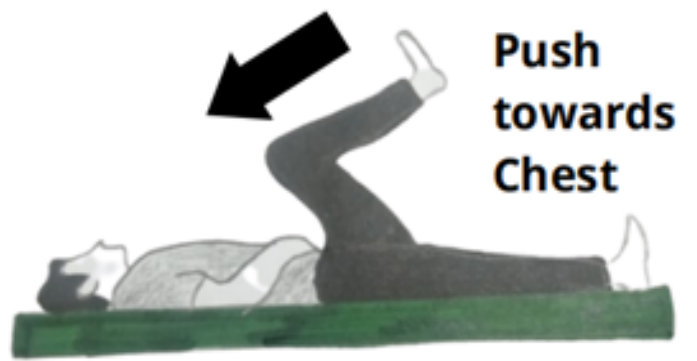

Figure-X: Displaying the hamstring stretch exercise. 


\section{Prescribed Duration:}

- Perform these exercises daily (once in a day).

- Initially perform each exercise slowly in a set of repetitions, as it gradually builds the body.

- Try to attain full ROM by moving to the phase of resistance (do not thrust a movement) and hold it for 30 seconds.

- Move deliberately and see the patient's facial response to ROM.

- Hold limbs firmly throughout motion.

\section{2) RECREATIONAL ACTIVITIES:}

As physical activities are important for every individual, recreational activities are also necessary to streamline the daily routine. As these activities motivates to do more, improves mental-health, provides freshness in mood and terminates anxiety and depression gradually. Following is some of the activities to perform especially in these crucial days of pandemic, when every person is quarantined in their homes:

- Staying all the time at home and especially in isolation is a stressful experience and can inhibit recovery. Greenery aids to reduce anxiety, stress and facilitates recovery specially for convalescing individuals ${ }^{[16,17]}$.

- Fresh air is a natural disinfectant as it is harmful to airborne bacteria and the influenza virus. Moreover, having sunlight for specific time period is beneficial for health and human immune system ${ }^{[18]}$.

- Talking is a fundamental part of human life, as it succour to hold good mental health. Being listened, helps you feel that other people care about you. Talking about your notions and thoughts can help you feel burdenless ${ }^{[19]}$.

- There is evidence of many distinguishable social-health and psychological benefits of participation in recreational activities. According to cross-sectional studies, such activities improve social-health and psychological issues, beside other types of leisure-time [20]. As reported by experimental studies, there is a vital role in reduction of depression and anxiety [21]. Research findings proves that engaging in creative activities improves mental health [22]. In reflection of such reports, in recent isolation every normal and disabled individual (specially children or adolescents) should perform recreational activities, as these all activities will work as a therapy and improve their mental health.

\section{DISCUSSION:}

Physical disabilities are usually provoked, when sensory nerves are damaged. Which results in the inability to sense pressure against the skin and if left unchecked, it could trigger a pressure ulcer. As individuals with physical disabilities often use wheelchairs or braces so they have a high risk of developing a pressure ulcer. It is necessary to recurrently check all exposed bodily parts for skin irritations and remain mobile. While, restricting themselves in a specific area can show adverse effects not only on physical-health, but also on mental-health. The survey emphasizes the harmful impact of the COVID-19 lockdown on the physical activity levels and mental health of impaired children and young people, as well as the significance of addressing the needs of the disabled population as limitations are lifted [23].

Thus, exercise positively improves mental health by minimizing depression, anxiety, moodswings and improves cognitive functions. Doing exercise alleviates symptoms and maintains physical-health as well as mental-health [24]. According to study, disabled individuals showed impressive improvements in balance control. Further reported as outcomes; reduction in blood pressure and obesity were seen while, fitness, exercise tolerance, energy and hand grip strength levels were increased. 30 minutes of moderate exercise, such as brisk walk for thrice a week is enough for well-being. Moreover, not performing it continuously as 3 reps of 10 -minute walk is more useful than one 30-minute walk ${ }^{[25]}$.

\section{CONCLUSION:}

As we know COVID-19 disease has hit the world as pandemic and damaged everything. Therefore, as a precautionary measure and a step to mitigate transmission of disease, nearly every person has confined himself in homes. Whereas, every person includes disable persons too and as we know this community of individuals are sensitive, emotional and weak. So, it is important to suggest particular recommendations regarding physical- 
health, which ultimately leads to improvements in mental-health too. Exercise is necessary to maintain physical fitness, digestive system, bone density, muscular strength, joint mobility, promotes physiological health with boosting immune system. Whereas, this study supports physically disabled persons and encourages them to do proper sets of exercise to maintain normal living.

ACKNOWLEDGEMENT: None. CONFLICT OF INTEREST:

It is to declare that, all the figures added in manuscript is my own imagination and there is no conflict of interest.

\section{GRANT SUPPORT \& FINANCIAL}

DISCLOSURE: None

\section{REFERENCES:}

1. UK Public General Acts. Disability Discrimination Act 1995: Disability Discrimination Act 1995 - revised version after 2002. Available from:https://www. legislation.gov.uk/ukpga/1995/50/contents

2. World Health Organization, International Classification of Functioning, Disability and Health (ICF) external icon. Geneva: 2001, WHO. Available from: https://www.who. int/standards/classifications/internationalclassification-of-functioning-disability-andhealth \# : : text =ICF\% 20 is $\% 20$ the $\% 20$ WHO\%20framework, and $\% 20$ measure $\% 20$ health\%20and\%20disability.

3. Rimmer JH, Marques AC. Physical activity for people with disabilities. The Lancet. 2012; 380(9838):193-195. Doi:10.1016/S01406736(12)61028-9

4. Titchkosky T. Disability, self, and society. University of Toronto Press; 2020.Doi: 10.3138/9781442673939

5. Wen CP, Wai JP, Tsai MK, Yang YC, Cheng TY, Lee $M C$, et al. Minimum amount of physical activity for reduced mortality and extended life expectancy: A prospective cohort study. The lancet. 2011;378(9798):1244-1253. Doi: 10.1016/S0140-6736(11)60749-6

6. Rimmer $\mathrm{JH}$. Exercise and physical activity in persons aging with a physical disability. Physical medicine and rehabilitation clinics of North America. 2005 ;16(1):41-56.
Doi:10.1016/j.pmr.2004.06.013

7. Worldometer, Daily cases world report; 2021 June 26 [cited 2020 Dec 12]. Available from:https://www. worldometers.info/coronavirus/?utm campaign=homeAdUOA?Si\%3Ca\%20href=

8. Lee IM, Shiroma EJ, Lobelo F, Puska P, Blair SN, Katzmarzyk PT. Lancet Physical Activity Series Working Group. Effect of physical inactivity on major non-communicable diseases worldwide: an analysis of burden of disease and life expectancy. The lancet. 2012;380(9838):219-229. Doi: 10.1016/ S0140-6736(12)61031-9

9. Rotarou ES, Sakellariou D, Kakoullis EJ, Warren N. Disabled people in the time of COVID-19: identifying needs, promoting inclusivity. Journal of Global Health. 2021;11: 03007. Doi: 10.7189/jogh.11.03007

10. International Committee of the Red Cross. Exercises for Lower-Limb Amputees: Gait Training; 2020.

11. Bosser G, Martinet N, Rumilly E, Paysant J, André JM. Exercise training for lower limb amputees. InAnnales de readaptation et de medecine physique: revue scientifique de la Societefrancaise de Reeducation Fonctionnelle de Readaptation et de MedecinePhysique. 2007; 51, (1):50-56.

12. Sol ME, Verschuren $O$, Horemans $H$, Westers $P$, Visser-Meily JM, et al. The effects of wheelchair mobility skills and exercise training on physical activity, fitness, skills and confidence in youth using a manual wheelchair. Disability and Rehabilitation. 2021:1-0. Doi: 10.1080/09638288.2021.1907456

13. Glaser RM. Arm exercise training for wheelchair users. Medicine and Science in Sports and Exercise. 1989 1;21(5 Suppl): S149-57.

14. Nagura $E$, Igata A, Fujita $H$, Inoue $T$, Kanno K, Matsuura T, et al. Characteristics of bedridden elderly people living at home and in a hospital. Nihon Ronen Igakkaizasshi. Japanese Journal of Geriatrics. 1997;34(7):589-595. Doi: 10.3143/geriatrics.34.589

15. Salz IW, Carmeli Y, Levin A, Fallach N, Braun $\mathrm{T}$, Amit S. Elderly bedridden patients with dementia use over one quarter of resources in internal medicine wards in an Israeli hospital. Israel Journal of Health Policy Research. 
2020； 9:1-5. Doi: 10.1186/s13584-02000379-0

16. Carver A, Lorenzon A, Veitch J, Macleod A, Sugiyama $T$. Is greenery associated with mental health among residents of aged care facilities? A systematic search and narrative review. Aging \& Mental Health. 2020;24(1): 17. Doi: $10.1080 / 13607863.2018 .1516193$

17. Williams F, Moghaddam N, Ramsden S, De Boos D. Interventions for reducing levels of burden amongst informal carers of persons with dementia in the community. A systematic review and meta-analysis of randomised controlled trials. Aging \& Mental Health. 2019;23(12):1629-1642. Doi: 10.1080/13607863.2018.1516193

18. Hiemstra JA, de Vries S, Spijker JH. Greenery and Healthcare: The Positive Effects of Greenery in Urban Environments.2019. https://edepot.wur.nl/418845

19. Akash A, Yar UB. House-Hold Safety Recommendations for COVID-19. Europasian Journal of Medical Sciences. 2020 24;2(2):3345. Doi: $10.46405 /$ ejms.v2i2.55

20. Smith K. Talking therapy: Knowledge and power in American psychiatric nursing. Rutgers University Press.2020.

21. Dishman RK. Physicalactivityand publichealth: mental health. Quest. 1995 1;47(3):362-385. Doi: $10.1080 / 00336297.1995 .10484164$

22. Emerson A. Creative Activities and Mental Health During the COVID-19 Pandemic. Murray State University. 2021.

23. Theis N, Campbell N, De Leeuw J, Owen M, Schenke KC. The effects of COVID-19 restrictions on physical activity and mental health of children and young adults with physical and/or intellectual disabilities. Disability and Health Journal. 2021:101064. Doi: $10.1016 /$ j.dhjo.2021.101064
24. Pascoe $M$, Bailey AP, Craike M, Carter T, Patten R, Stepto N, et al. Physical activity and exercise in youth mental health promotion: A scoping review. BMJ Open Sport \& Exercise Medicine. 2020;6(1): e000677.Doi: 10.1136/ bmjsem-2019-000677

25. Sharma A, Madaan V, Petty FD. Exercise for mental health. Prim Care Companion Journal of Clinical Psychiatry. 2006;8(2):106.Doi: 10.4088/pcc.v08n0208a.

\section{AUTHORS CONTRIBUTION:}

Usama Bin Yar: Writer and illustration making
Submitted for Publication: 15-01-2021 Accepted After revision: 29-06-2021 